\title{
Response of Gram-positive bacteria to copper stress
}

\author{
Marc Solioz · Helge K. Abicht · Mélanie Mermod • \\ Stefano Mancini
}

Received: 12 August 2009/Accepted: 1 September 2009/Published online: 23 September 2009

(C) SBIC 2009

\begin{abstract}
The Gram-positive bacteria Enterococcus hirae, Lactococcus lactis, and Bacillus subtilis have received wide attention in the study of copper homeostasis. Consequently, copper extrusion by ATPases, gene regulation by copper, and intracellular copper chaperoning are understood in some detail. This has provided profound insight into basic principles of how organisms handle copper. It also emerged that many bacterial species may not require copper for life, making copper homeostatic systems pure defense mechanisms. Structural work on copper homeostatic proteins has given insight into copper coordination and bonding and has started to give molecular insight into copper handling in biological systems. Finally, recent biochemical work has shed new light on the mechanism of copper toxicity, which may not primarily be mediated by reactive oxygen radicals.
\end{abstract}

Keywords Copper homeostasis - Toxicity ·

Copper ATPases - Gene regulation - Copper chaperones

\section{Introduction}

The differentiation of bacteria into Gram-positive and Gram-negative organisms by Gram staining, a method developed by the Danish scientist Hans Christian Gram in

This article will be printed in the upcoming Journal of Biological Inorganic Chemistry special issue CELL BIOLOGY OF COPPER.

M. Solioz $(\bowtie) \cdot$ H. K. Abicht · M. Mermod · S. Mancini Department of Clinical Pharmacology and Visceral Research, University of Berne,

Murtenstrasse 35,

3010 Berne, Switzerland

e-mail: marc.solioz@ikp.unibe.ch
1884 , has remained alive to this day. This is due to the fact that Gram staining conveniently differentiates between organisms with an inner and an outer cell membrane and a cell wall between (Gram-negative) and those with only a single cell membrane surrounded by the cell wall (Grampositive). Traditionally, Gram-positive organisms are of the phyla Actinobacteria and Firmicutes; the latter includes the genera Bacillales, Clostridia, Lactobacillales, and Mollicutes. Some Mollicutes (e.g. Mycoplasma) lack a cell walls and thus cannot be Gram-stained, but phylogenetically belong to the Gram-positive bacteria. Since very little is known about their copper metabolism, they will not be further discussed here. Actinobacteria is the other major group of Gram-positive bacteria. In contrast to the members of Firmicutes, members of Actinobacteria have a high guanosine plus cytosine content in their genomes. Members of Firmicutes are acid-tolerant, mostly nonsporulating, and generally facultative anaerobic bacteria. Gram-positive organisms in general occupy a variety of habitats, ranging from soil and water to decomposing plants and mammalian gut or oral flora, thereby also being potentially pathogenic [1].

Of the Gram-positive bacteria, lactic acid bacteria have received the widest attention owing to their extensive use in food production and preservation. The eponymous trait of these organisms, namely, the production of acid during carbohydrate fermentation, generates a very acidic environment [2]. This is often accompanied by the secretion of bacteriocins, such as nisin. Bacteriocins are proteinaceous toxins which inhibit the growth of similar or closely related bacterial strains. The combined action of low $\mathrm{pH}$ and bacteriocins efficiently inhibits the growth of competing bacteria, a property which is made use of in food preservation [3]. However, the acidic ambient condition can lead to the solubilization of complexed metal ions, thus 
generating unfavorably high metal ion concentrations. For example, in traditional cheese making, mostly involving members of the genus Lactococcus, the cells are challenged by copper released from the copper vats [4]. Copper is one of the metal ions known to exert toxic effects on bacteria and other organisms. Excess copper avidly binds to many biomolecules such as proteins, lipids, and nucleic acids, regardless of its valence state [5]. But in contrast to other toxic metals such as silver and lead, copper is also an essential trace nutrient. Bacteria therefore evolved tight copper homeostatic control mechanisms, involving copper binding and transport and the regulation of gene expression by copper. Work chiefly on Enterococcus hirae, Lactococcus lactis, and Bacillus subtilis has provided profound insight into basic principles of how Gram-positive organisms handle copper. Key aspects of copper handling by Gram-positive organisms will be discussed in this review.

\section{Copper as a bioelement}

Because of copper's ability to cycle between $\mathrm{Cu}^{2+}$ and $\mathrm{Cu}^{+}$at biologically relevant redox potentials, it has become a cofactor for over 30 known enzymes in higher organisms [6]. Prominent examples are lysyl oxidase, involved in the cross-linking of collagen, tyrosinase, required for melanin synthesis, dopamine $\beta$-hydroxylase of the catecholamine pathway, cytochrome $c$ oxidase as a terminal electron acceptor of the respiratory chain, and superoxide dismutase, required for defense against oxidative damage. Members of another class of copper proteins, such as plastocyanins and azurins, act as electron carriers. Depending on the type of coordination of the copper to the protein, the redox potential can vary over the range from 200 to $800 \mathrm{mV}$. Concomitant with the lower complexity of bacteria, only ten cuproenzymes have so far been characterized in microbes (Table 1). However, it is likely that many cuproenzymes have not yet been identified in eukaryotes as well as in prokaryotes.
In the primordial, anaerobic world, copper was in the $\mathrm{Cu}(\mathrm{I})$ state in the form of water-insoluble sulfides under neutral pH conditions and was only bioavailable in the acidic waters near hydrothermal vents. The emergence of an oxygen-containing atmosphere by the action of oxygenevolving microorganisms, probably cyanobacteria, less than $3 \times 10^{9}$ years ago was a dramatic event for most living organisms [17]. It could be considered as an early, irreversible pollution of the earth. Most living organisms adapted to the new conditions by acquiring an oxidative metabolism. Enzymes involved in anaerobic metabolism were designed to operate in the lower portion of the redox spectrum. The arrival of dioxygen created the need for a new redox-active metal that could attain higher redox potentials. The oxidation of insoluble $\mathrm{Cu}(\mathrm{I})$ led to soluble and thus widely bioavailable $\mathrm{Cu}(\mathrm{II})$, which was ideally suited to exploit the oxidizing power of dioxygen [18]. Copper therefore is a modern bioelement [19]. Concomitant with the arrival of oxygen, multicellular organisms developed.

Interestingly, not all bacteria appear to have acquired cuproenzymes and at the current state of knowledge a distinction can be made between copper "users" and "nonusers" (Table 2). This information has been derived from a bioinformatics analysis of sequenced microorganisms [20]. Strikingly, only about half of the members of Firmicutes analyzed appear to be copper users. The definition of "users" here is based on the currently known bacterial cuproenzymes as outlined in Table 1 . It cannot be precluded that new functions of copper will emerge that are also found in the nonusers. But this will not change the basic observation that some bacteria make extensive use of copper as a bioelement, whereas others appear to avoid it. Interestingly, members of Firmicutes, which are users, have an average genome size of $3 \mathrm{Mb}$, whereas the average genome size of nonusers is only 2.3 Mb [20]. The reason for this is not known.

Recently, an unexpected link between copper and molybdenum cofactor (MOCO) synthesis was discovered.
Table 1 Known bacterial copper-containing enzymes

\begin{tabular}{lll}
\hline Enzyme & Function & References \\
\hline Cytochrome $c$ oxidase & Terminal oxidase & {$[7]$} \\
NADH dehydrogenase-2 & Electron transport, copper reduction & {$[8,9]$} \\
Nitrosocyanin, cuproredoxin-like & Electron transfer, other? & {$[10]$} \\
Plastocyanins & Electron transfer & {$[7]$} \\
Cu-containing nitrite reductases & Nitrous oxide reduction & {$[11]$} \\
Tyrosinase & Phenol oxidation, melanin synthesis & {$[12,13]$} \\
Copper amine oxidases & Oxidation of primary amines & {$[14]$} \\
Particulate methane monooxygenase & Methane oxidation & {$[15]$} \\
Copper-containing laccase & Polyphenol oxidase & {$[16]$} \\
\hline
\end{tabular}


Table 2 Occurrence of cuproenzymes in Gram-positive bacteria (from [20])

\begin{tabular}{llll}
\hline Organisms & $\begin{array}{l}\text { Number of } \\
\text { genomes }\end{array}$ & $\begin{array}{l}\text { Number of } \\
\text { "users" }\end{array}$ & $\begin{array}{l}\text { MOCO } \\
\text { synthesis }\end{array}$ \\
\hline $\begin{array}{l}\text { Actinobacteria } \\
\text { Firmicutes }\end{array}$ & 38 & 34 & 31 \\
Bacillales & 19 & 17 & 18 \\
Clostridia & 17 & 0 & 16 \\
Lactobacillales & 22 & 0 & 4 \\
Mollicutes & 17 & 0 & 0 \\
\hline
\end{tabular}

MOCO molybdenum cofactor

Plant Cnx1G, a domain of the Cnx1GE protein, catalyzes the adenylation of molybdopterin. Cnx1G-bound molybdopterin was found to have copper bound to the molybdopterin dithiolate sulfurs [21]. The function of this bound copper is presently unknown, but copper might play a role in protecting the molybdopterin dithiolate from oxidation, and/or in presenting a suitable leaving group for molybdenum insertion [22]. It remains currently unclear if the binding of copper to molybdopterin is an essential step in MOCO synthesis, but if so, this pathway generates a copper requirement in addition to those considered in Table 1 [23]. Approximately $70 \%$ of the Gram-positive organisms are capable of synthesizing MOCO; of these, $85 \%$ are also copper users (Table 2). Only members of Clostridia and a few of the members of Lactobacillales appear to be copper nonusers and still capable of MOCO synthesis. The cooccurrence of copper use and MOCO synthesis can be observed across most bacterial phyla. Whether this has a biological significance remains open.

In line with the abundance of apparent copper nonusers, very few bacterial copper importers have been described. All sequenced microorganisms do, however, possess one or several defense systems against copper toxicity. An explanation for this could lie in the evolution of the first life forms in volcanic environments, such as deep-sea volcanic vents, 3.5 billion years ago [24, 25]. Owing to the high temperature and acidity, such environments are rich in dissolved heavy-metal ions [26], making defense mechanisms against these potentially toxic elements an evolutionary priority. Systems for copper defense and copper utilization may thus have evolved independently of each other.

In eukaryotic organisms, there is a clear requirement for copper import into the cytoplasm for the synthesis of cytoplasmic cuproenzymes, but also for enzymes synthesized in organelles, such as cytochrome $c$ oxidase in mitochondria, and tyrosinase and ceruloplasmin in the endoplasmatic reticulum [27]. Eukaryotes therefore have copper importers, such as Ctr1, in the plasma membrane. In contrast, bacteria may not have a general requirement for cytoplasmic copper. Cyanobacteria (e.g., Synechocystis) are the one bacterial group that has a known demand for cytoplasmic copper for the synthesis of copper-containing, thylakoid-localized plastocyanin and cytochrome oxidase [28]. In other organisms, the cuproenzymes are localized to the cytoplasmic membrane or the periplasm and copper loading of these proteins could take place at the cytoplasmic membrane or in the periplasm. Thus, many bacteria, particular Gram-positive ones, do not appear to have a requirement for intracellular copper, and the copper homeostatic machinery in these organisms may have the sole purpose of keeping copper out. This concept is supported by the complete absence of copper chaperones in many bacteria, whereas copper chaperones are essential in eukaryotes for delivering copper to enzymes such as cytochrome $c$ oxidase and superoxide dismutase [29].

\section{Novel copper toxicity mechanisms}

The major toxic effect of copper has frequently been claimed to be due to the generation of toxic reactive oxygen species in a Fenton-type reaction [30], leading to the generation of hydroxyl radicals $(\mathrm{OH} \cdot)$, hydrogen peroxide $\left(\mathrm{H}_{2} \mathrm{O}_{2}\right)$, and superoxide $\left(\mathrm{O}_{2}^{-}\right)$. Alternatively, sulfhydryl depletion by reactions 1 and 2 has been put forth as a celldamaging mechanism.

$$
\begin{aligned}
& 2 \mathrm{Cu}^{2+}+2 \mathrm{RSH}=2 \mathrm{Cu}^{+}+\mathrm{RSSR}+2 \mathrm{H}^{+} \\
& 2 \mathrm{Cu}^{+}+2 \mathrm{H}^{+}+\mathrm{O}_{2}=2 \mathrm{Cu}^{2+}+\mathrm{H}_{2} \mathrm{O}_{2}
\end{aligned}
$$

Although lipid, protein, and nucleic acid damage by these mechanisms has been demonstrated in vitro in many studies, recent findings suggest an alternative mechanism to be responsible for the primary toxic effects of copper in vivo. First, the discovery that free copper in the cell is at extremely low levels or even nonexistent makes Fenton chemistry and sulfhydryl depletion very unlikely mechanisms [31]. Second, many Gram-positive organisms are rather tolerant to $\mathrm{H}_{2} \mathrm{O}_{2}$. For example, L. lactis IL1403, described in some detail below, generates $\mathrm{H}_{2} \mathrm{O}_{2}$ by NADH dehydrogenation, but does not possess catalase for $\mathrm{H}_{2} \mathrm{O}_{2}$ removal [32-34]. Third, Macomber et al. [35] recently showed that copper-loaded Escherichia coli was less sensitive to killing by $\mathrm{H}_{2} \mathrm{O}_{2}$ than $E$. coli cells grown without copper. Also, copper decreased the rate of $\mathrm{H}_{2} \mathrm{O}_{2}$-induced DNA damage. High intracellular copper levels even impaired iron-mediated oxidative killing by $\mathrm{H}_{2} \mathrm{O}_{2}$. The authors suggested that copper exerts its toxicity by mechanisms other than oxidative stress.

A novel mechanism of copper toxicity was indeed recently demonstrated. It could be shown in vivo as well as in vitro that copper specifically damaged the iron-sulfur 
clusters of isopropylmalate dehydratase of E. coli [36]. This enzyme of the branched-chain amino acid biosynthesis pathway contains an iron-sulfur cluster from which the iron can be displaced by copper in the absence of oxygen. Copper efflux systems, chelation by glutathione, and cluster repair by assembly systems all enhance resistance of cells to this type of copper toxicity. To establish whether this mechanism is a general route of copper toxicity in bacteria, including Gram-positive organisms, will require further investigation.

\section{Copper homeostasis in Gram-positive organisms}

The copper homeostatic system of E. hirae is the best understood of those in Gram-positive bacteria and has served as a model for metal homeostasis in general [37]. The core element is an operon which consists of the four genes $\operatorname{cop} Y, \operatorname{cop} Z, \operatorname{cop} A$, and $\operatorname{cop} B$. The genes $\operatorname{cop} A$ and сор $B$ encode copper-transporting ATPases (Fig. 1). These ATPases mark the discovery of ATP-driven transmembranous copper transport in 1992 [38]. The gene product of copY encodes a copper-responsive repressor which derepresses transcription of the cop operon under conditions of copper excess (see below). The copZ gene, finally, encodes a copper chaperone which serves in the intracellular routing of copper. The cop operon enables $E$. hirae to grow in up to $8 \mathrm{mM}$ copper and under copper-limiting conditions.

It is assumed that CopA acquires copper under lowcopper conditions, whereas CopB extrudes excess copper,

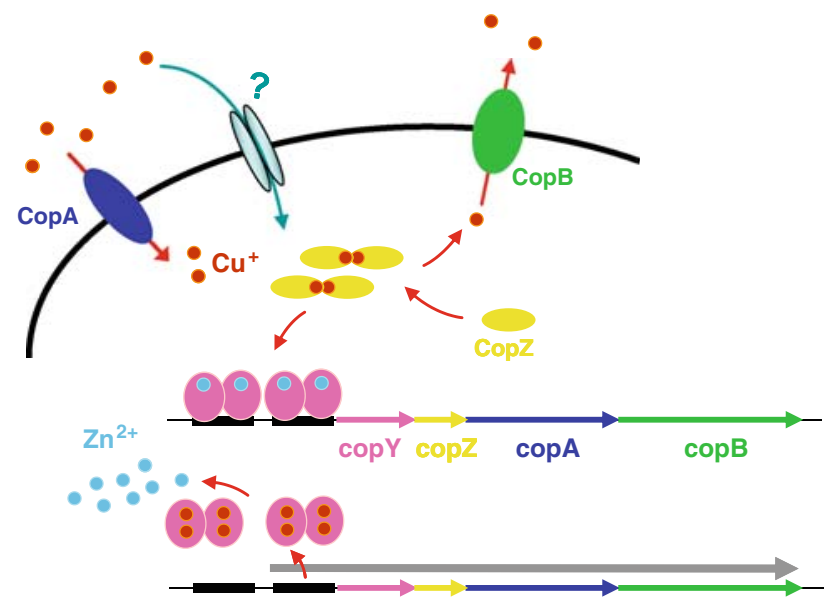

Fig. 1 Copper homeostasis in Enterococcus hirae. Copper enters the cell via CopA or by nonspecific leakage. Excess cytoplasmic copper binds to $\mathrm{CopZ}$, which can then donate $\mathrm{Cu}^{+}$to $\mathrm{CopB}$ for export and to the CopY repressor to induce the cop operon. In low copper conditions, two CopY dimers in the zinc form are bound to the two cop boxes in front of the cop operon. When CopZ donates $\mathrm{Cu}^{+}$to CopY, one $\mathrm{Zn}^{2+}$ per CopY monomer is replaced by two $\mathrm{Cu}^{+}$, with concomitant release of CopY from the promoter and induction of transcription of the downstream genes and also silver [39, 40], when these ions are in excess. In Gram-positive bacteria, cytoplasmic enzymes that require copper are unknown. Nevertheless, specific copper importers that are expressed under copper-limiting conditions have been described in E. hirae, Listeria monocytogenes, and B. subtilis [41-43]. Energy-dependent copper uptake has not yet been directly demonstrated in any of these organisms and copper uptake in other ways such as copper complexed to copper chalkophores [44, 45] or as copper-substrate complexes through substrate transporters remain open possibilities [30].

YcnJ has recently been shown to be a candidate for a copper uptake pump in B. subtilis. The $y c n J$ gene showed a strong upregulation under copper-limiting conditions and a $\Delta y c n J$ strain grew poorly under copper deprivation. On native gels, the periplasmic $\mathrm{N}$-terminal domain (135 amino acids) of $\mathrm{YcnJ}$ oligomerized in the presence of $\mathrm{Cu}$ (II), but not $\mathrm{Cu}(\mathrm{I})$. Hence, in contrast to CopA of E. hirae, YcnJ was suggested to import copper in its divalent state [43]. Further characterization of this import system is, however, still required.

Current evidence that CopA of E. hirae is involved in copper import is based on the following observations: (1) $\triangle$ copA strains grow poorly in media where copper is limited by complexation with copper chelators and (2) $\Delta c o p A$ strains are more resistant to $\mathrm{Ag}^{+}$than the wild type, presumably because CopA can be a route for entry of silver into the cell [40]. Purified CopA was shown to catalyze ATP hydrolysis and to form an acylphosphate intermediate, which was inhibited by vanadate, a characteristic inhibitor of P-type ATPases. Inhibition was also detected in the presence of $\mathrm{Cu}(\mathrm{I})$ chelators, but not with $\mathrm{Cu}(\mathrm{II})$ chelators, supporting a role of CopA in the transport of $\mathrm{Cu}^{+}$ions [42]. However, the postulate that CopA of E. hirae serves in copper import still awaits rigorous experimental confirmation.

Copper secretion by copper ATPases for the rapid export of excess copper out of the cytosol is common, if not ubiquitous, and is the basic mechanism of bacterial copper resistance. The process has been documented in many eukaryotic and bacterial systems. In E. hirae, CopB is responsible for copper export. $\mathrm{Cu}^{+}$transport and $\mathrm{Ag}^{+}$ transport by this enzyme have been directly demonstrated with radioisotopes in membrane vesicles and in whole cells loaded with silver [39, 40]. CopB features, unlike other copper ATPases, a histidine-rich $\mathrm{N}$-terminus instead of a CxxC motif. Similar histidine repeat structures were found in two Pseudomonas syringae proteins which were demonstrated to be periplasmic copper-binding proteins [46]. In B. subtilis, the copper export pump CopA features two $\mathrm{N}$-terminal domains, each containing a $\mathrm{Cu}^{+}$-binding motif, CxxC. It was shown that these motifs play a role in dimerization of CopA under high copper concentrations (more than one copper ion per protein; [47, 48]). 


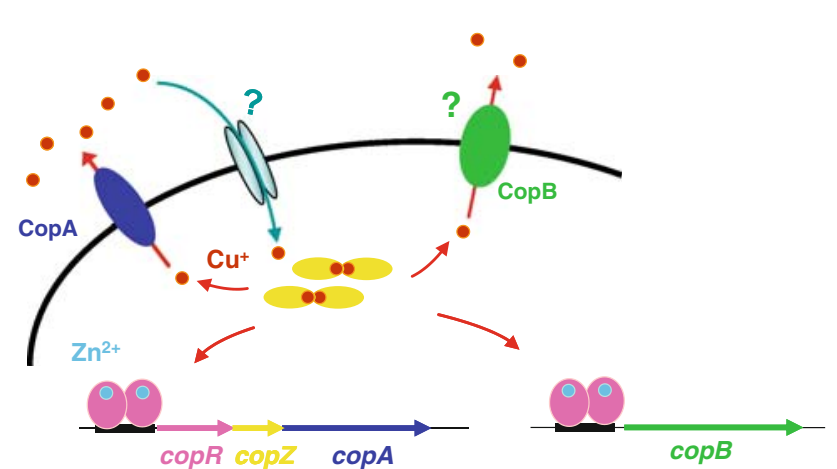

Fig. 2 Copper homeostasis in Lactococcus lactis. How copper enters the cell is unknown. Excess cytoplasmic copper binds to CopZ, which can then donate $\mathrm{Cu}^{+}$to either the copper ATPases for export or the CopR repressor to induce transcription. In low-copper conditions, a CopR dimer in the zinc form is bound to the cop box in front of the copRZA operon and the $\operatorname{cop} B$ gene. When CopZ donates $\mathrm{Cu}^{+}$to CopR, one $\mathrm{Zn}^{2+}$ per CopR monomer is replaced by two $\mathrm{Cu}^{+}$, with concomitant release of CopR from the promoters and induction of transcription of the downstream genes. CopA then accomplishes copper export from the cytoplasm. The function of CopB is unknown

In L. lactis IL1403, the copper-inducible copRZA operon encodes the CopR repressor, a CopY-type repressor, the CopZ copper chaperone, and the CopA copper ATPase (Fig. 2). The latter exhibits $45 \%$ sequence identity to CopA of $E$. hirae. This enzyme has been proposed to serve as a copper importer [37, 40, 49] under copper-limiting conditions. The nomenclature of CopA ATPases is thus confusing: with the exception of CopA of E. hirae, CopA copper ATPases export copper and have a role in copper resistance in all other organisms. Also in L. lactis, CopA clearly serves in copper extrusion [50]. The CopR repressor of $L$. lactis regulates the CopR regulon in a fashion analogous to CopY in E. hirae. The CopZ-like copper chaperone can be assumed to function in intracellular copper routing like CopZ of E. hirae [51, 52].

A second putative copper ATPase in L. lactis is encoded by the unlinked, monocistronic $\operatorname{cop} B$ gene, which is also under the control of CopR. CopB features a histidine-rich $\mathrm{N}$-terminus and shares $55 \%$ sequence identity with $E$. hirae CopB. However, a function of L. lactis CopB in copper export has not yet been demonstrated. It is notable that $E$. hirae CopB is encoded by the $\operatorname{cop} Y Z A B$ operon, whereas CopB of L. lactis is encoded by a monocistronic gene. Whether these different gene organizations in L. lactis and $E$. hirae are a consequence of functional differences remains an open question.

\section{Copper-responsive repressors}

Copper-responsive transcriptional regulators detect excessive copper ions in the cell and modulate the transcription of genes and operons with roles in copper homeostasis,
Table 3 Distribution of copper-responsive regulators in Gram-positive bacteria and proteobacteria

\begin{tabular}{lccc}
\hline Organisms & CopY-type & CsoR-type & CueR-type \\
\hline Actinobacteria & 0 & 43 & 0 \\
Firmicutes & & & \\
Bacillales & 3 & 30 & 7 \\
Clostridia & 0 & 25 & 0 \\
Lactobacillales & 39 & 3 & 0 \\
Proteobacteria & 0 & 54 & 215 \\
\hline
\end{tabular}

thereby ensuring a proper balance of copper ions in the cell. In Gram-positive bacteria, two families of copperresponsive transcriptional regulators appear to regulate copper homeostasis (Table 3). These are, named by their founding members, the CopY-and the CsoR-type regulators [53]. CopY-type regulators have experimentally been associated with gene regulation by copper in E. hirae [54], Enterococcus faecium [55], L. lactis IL1403 [50], Streptococcus mutans [56, 57], and Streptococcus gordonii [58].

CsoR-type regulators have only recently been described, although their occurrence is more widespread, and they are abundant not only in Gram-positive organisms, but also in members of Proteobacteria [53]. CsoR-related proteins may in fact be the primary copper sensors in prokaryotes which lack CueR-type regulators. In over $70 \%$ of the identified CsoR-type repressors, all three copper binding ligands were conserved. Also, many of the repressor genes were adjacent to either putative copper ATPase or copper chaperons. In more distantly related CsoR homologous, not all three copper ligands were conserved and some of these genes are adjacent to permease genes, homologous to the major facilitator superfamily. These efflux proteins may mediate multidrug resistance, thereby raising the intriguing hypothesis that some CsoR-encoding genes may have evolved to sense organic molecules [53].

CueR-type regulators, which regulate copper homeostatic genes in E. coli [59], occur in a few species of Bacillales. However, the initial claim that CueR of B. subtilis regulates the expression of the copZA operon in this organism [60] was later refuted and it was shown that a CsoR-type regulator controls copZA expression [61]. It thus remains unclear if CueR-type regulators have a role in copper homeostasis by Gram-positive organisms. CueRtype regulators appear to be a typical feature of the Gramnegative proteobacteria and will not be discussed further.

\section{CopZ-type copper chaperones}

Since excess copper can produce cellular damage, cells need to keep the intracellular concentration of free copper ions very low. On this account, specific copper chaperones 
have evolved that tightly bind copper ions and escort them from the point of entry to target enzymes. There is a range of copper chaperones in all eukaryotes to deliver copper to copper ATPases, cytochrome $c$ oxidase, or superoxide dismutase [29]. The 8-kDa Atx1-like chaperones, first described in yeast [62], have been found in all organisms, including mammals, plants, insects, fungi, and bacteria [63]. In bacteria, these copper chaperones are usually called CopZ, based on the founding member, CopZ of E. hirae [64]. However, many bacterial species, including E. coli, do not appear to possess a copZ gene. Among the Gram-positive bacteria, Actinobacteria are devoid of CopZ, whereas most, if not all other Gram-positive bacteria possess CopZ. Since the gene is small and does not always start with methionine, it may not have been discovered in all sequenced genomes.

Bacteria may be devoid of copper chaperones, or may feature only a CopZ-like or a Sco-like chaperone [65]. Sco-like proteins can be found in Gram-positive organisms $[66,67]$ and exhibit a thioredoxin-like fold [68]. B. subtilis possesses a Sco-like chaperone, YpmQ or BSco, with a proposed function in delivering copper to cytochrome $c$ oxidase [69]. In contrast, a new periplasmic protein, $\mathrm{PCu}_{\mathrm{A}} \mathrm{C}$, was recently shown to selectively insert $\mathrm{Cu}(\mathrm{I})$ into the $\mathrm{Cu}_{\mathrm{A}}$ site of the $b a_{3}$ oxidase of Thermus thermophilus [70]. Sco1 was unable to deliver copper to the oxidase, but worked as a thiol disulfide reductase to maintain the correct oxidation state of the $\mathrm{Cu}_{\mathrm{A}}$ cysteine ligands. This finding and the fact that some organisms possess Sco-like proteins but no cytochrome $c$ oxidase [71] suggests diverse roles for Sco-like proteins in the assembly of cuproenzymes.

Many structures for Atx1- or CopZ-like metallochaperones have been solved (see [72] for a review). They all share the same $\beta \alpha \beta \beta \alpha \beta$ ferredoxin-like structure, with two cysteines of a $\mathrm{CxxC}$ motif located in a loop between $\beta 1$ and $\alpha 1$ (Fig. 3). There is still uncertainty as to how $\mathrm{Cu}^{+}$is complexed by the chaperone in vivo. $\mathrm{Cu}^{+}$can in principle bind to the two solvent-exposed cysteines, located at one end of the molecule, in a near-linear $\mathrm{S}-\mathrm{Cu}-\mathrm{S}$ bonding. However, $\mathrm{X}$-ray structures of Hah1, the human CopZ-like copper chaperone, have revealed structures where a single $\mathrm{Hg}^{2+}$ or $\mathrm{Cu}^{+}$ion is complexed by the four cysteines of two chaperones in a dimeric arrangement [73]. $\mathrm{Cu}^{+}-\mathrm{CopZ}$ of E. hirae, on the other hand, appeared to be dimeric in solution, with trigonally bound copper the most likely structure (Fig. 4) [74]. The prevalence of homodimeric $\mathrm{Cu}^{+}-\mathrm{CopZ}$ was also demonstrated by biochemical and light-spectroscopic techniques [75, 76]. A three-coordinate metal center is also supported by extended X-ray absorption fine structure measurements of $\mathrm{Cu}^{+}$-thiol bonds [74, 77]. Glutathione was shown to inhibit dimer formation in vitro and could, in principle, be a ligand to monomeric $\mathrm{Cu}^{+}-$ CopZ inside the cell, where glutathione concentrations are

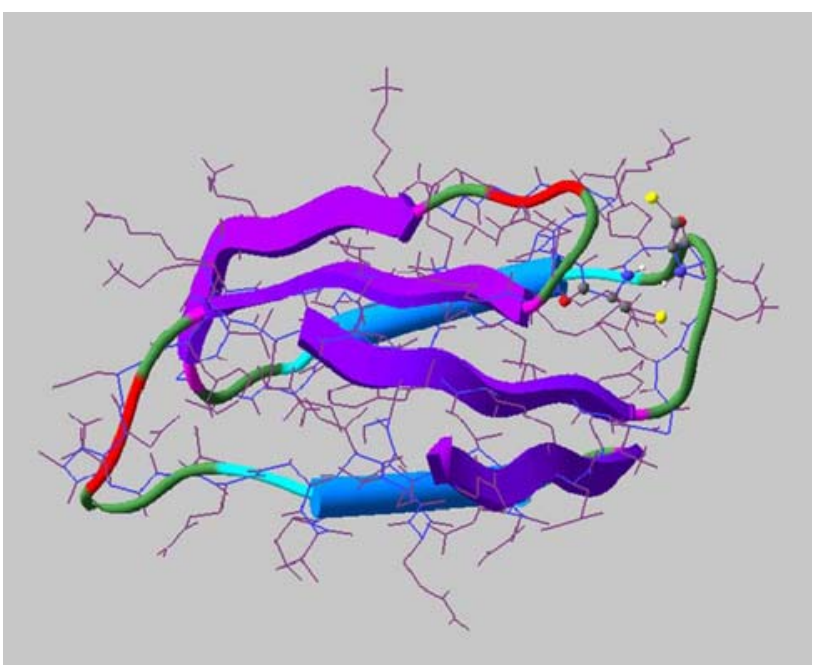

Fig. 3 Structure of CopZ of E. hirae. The protein is folded in a $\beta \alpha \beta \beta \alpha \beta$ structure. Note the exposed cysteines (yellow) which serve to bind $\mathrm{Cu}^{+}$

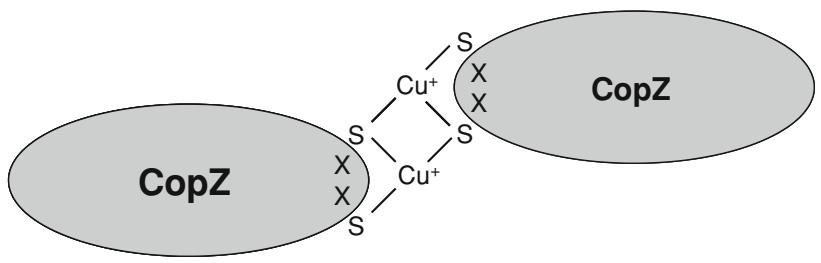

Fig. 4 Model of $\mathrm{Cu}^{+}-\mathrm{CopZ}$ dimer formation. Each $\mathrm{Cu}^{+}$ion is coordinated by three sulfur atoms of the cysteine ligands of two CopZ molecules

high. It is also conceivable that there is an equilibrium between monomeric, dimeric, and even trimeric CopZ in the cell, but this will be very difficult to assess. How CopZ interacts with CopY-type repressors and copper ATPases will be discussed in detail in the following sections.

At high intracellular copper levels CopZ appears to be degraded through a proteolytic pathway [78]. This observation led to the proposal that high levels of CopZ may be toxic to the cell; however, the mechanisms of toxicity and degradation are still unclear.

\section{Function of CopY-type repressors}

CopY and related repressors modulate the expression of genes in response to copper in most, if not all, species of Lactobacillales. Like many bacterial regulators, CopY-type repressors have a bipartite structure. The $\mathrm{N}$-terminal domain is responsible for the interaction with DNA, and the C-terminus interacts with zinc or copper. The N-terminus of CopY of $E$. hirae shows extensive sequence similarity to BlaI, MecI, and PenI, which are repressors involved in the regulation of $\beta$-lactamase in Gram-positive 
A

BlaI IS..EW.VM..IW............TL..RL.KKE

MecI IS..EWEVM..IW........... .TL..RL.KK.

PenI ISD.E.EVM.VIW.............T.T.R.R.KK.

$\begin{array}{rrrrr}\text { MEEKRVLIKISDSEWEVMRVIWTLGQANAQQITQ . . ATVKTLLGRLVKKEAL } \\ 10 & 20 & 30 & 50 & 60\end{array}$

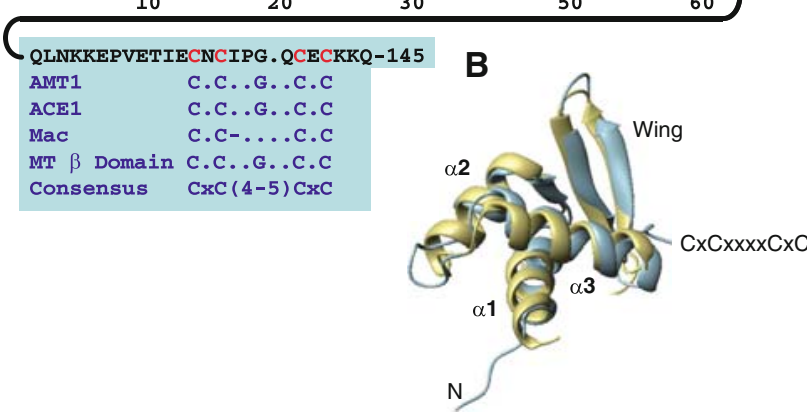

Fig. 5 a Alignment of the protein sequence of CopY of E. hirae with those of $\beta$-lactamase regulators in the $\mathrm{N}$-terminal region and fungal transcriptional regulators and metallothionein in the $\mathrm{C}$-terminal region. b Overlay of the $\mathrm{N}$-terminal DNA binding domain of L. lactis CopR (blue) and the BlaI $\beta$-lactamase regulator of Bacillus licheniformis (gold)

bacteria (Fig. 5a) [79-82]. The structure of the N-terminus of CopR of L. lactis, a CopY homologue, has been solved by solution NMR [83] and in fact is nearly superimposable on the structure of BlaI of Bacillus licheniformis (Fig. 5b). The C-termini of the latter type of repressors and their mode of induction by proteolysis are entirely different from those of CopY-type repressors [84]. The C-terminus of CopR exhibits sequence similarity to the yeast copperinducible repressors AMT1, ACE1, and Mac, and to the $\beta$-domain of metallothioneins [85]. All these proteins feature the consensus motif $\mathrm{CxCx}_{4-5} \mathrm{CxC}$. In the newly synthesized CopY-type repressors, this site is occupied by a single $\mathrm{Zn}^{2+}$, which is coordinated by four sulfur atoms in a tetrahedral fashion.

At low ambient copper concentrations, CopY is present as a $\mathrm{Zn}$ (II)-containing homodimer and is bound to the operator-promoter region of the operon [54]. The CopY dimer binding sites feature the so-called cop box of consensus TACAnnTGTA, a motif which is widely conserved in members of Lactobacillales. The DNA-CopY interaction has been assessed in quantitative terms by surface plasmon resonance analysis [57]. It was found that the CopY-type repressors of L. lactis, E. hirae, and S. mutans had very similar affinities for either their native promoters or heterologous promoters, as long as they contained the cop-box. It could also be shown that the induction of the CopY repressor by copper resulted in a relatively moderate change of the DNA dissociation rate constant, $k_{\mathrm{d}}$, from $1 \times 10^{-7}$ to $5 \times 10^{-7} \mathrm{~s}^{-1}$ [86]. Interestingly, the $\beta$-lactamase regulators which feature an N-terminal DNA binding domain essentially identical to CopY-like repressors also recognize a "cop box" [87]; the possible consequences of this have not been investigated.

For unknown reasons, there are two cop boxes upstream of the E. hirae cop operon, but the majority of CopYcontrolled genes or operons feature only a single cop box. Under low-copper conditions, a CopY dimer is bound to each cop box and prevents transcription. When the level of medium copper is raised, $\mathrm{Cu}^{+}-\mathrm{CopZ}$ donates $\mathrm{Cu}(\mathrm{I})$ to CopY. This displaces the bound $\mathrm{Zn}(\mathrm{II})$ and $\operatorname{CopY}$ is released from the DNA, allowing transcription to proceed (Fig. 6) $[51,88] . \mathrm{Cu}^{+}$in $\mathrm{CopY}$ is trigonally bound by cysteines and solvent-shielded. This makes the protein luminescent, a typical property of solvent-shielded copper thiolates. The induction mechanism of CopY is
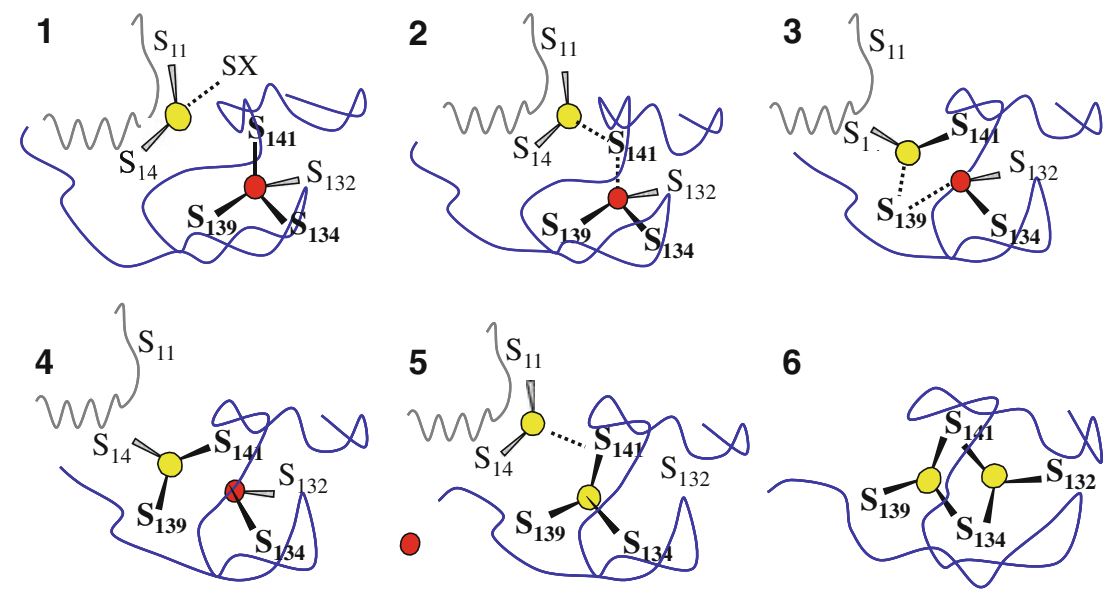

Fig. 6 Model of $\mathrm{Cu}^{+}$transfer from $\mathrm{Cu}^{+}-\mathrm{CopZ}$ to $\mathrm{Zn}^{2+}-\mathrm{CopY}$. $1 \mathrm{Cu}^{+}$bound to the sulfur atoms of the cysteines of $\mathrm{C} 11$ and $\mathrm{C} 14$ (S11, S14) of CopZ and probably a third ligand (e.g., glutathione) approaches CopY. $2 \mathrm{~S} 141$ of CopY interacts with the $\mathrm{Cu}^{+}$, thereby destabilizing the corresponding $\mathrm{S}-\mathrm{Zn}$ bond in CopY. 3, 4 a second
$\mathrm{Cu}-\mathrm{S}$ bond with $\mathrm{CopY}$ is made, further destabilizing the zinc binding. $5 \mathrm{Zn}^{2+}$ is released from CopY and one $\mathrm{Cu}^{+}$is now bound to CopY in a triagonal $\mathrm{Cu}-\mathrm{S}_{3}$ coordination, thermodynamically aided by a second, incoming $\mathrm{Cu}^{+} .6 \mathrm{CopY}$ in the final $\left(\mathrm{Cu}^{+}\right)_{2}$-CopY form 


\section{A}

Copz -K-----K---C--C------------KK-K---KK-K---K

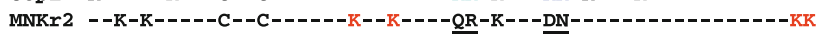

B
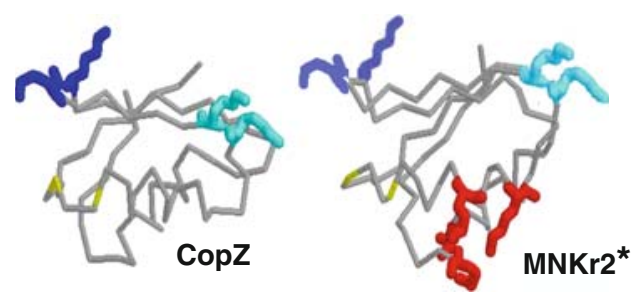

Fig. 7 Gain-of-function engineering of MNKr2. a Positions of lysine residues and the two copper-binding cysteines along the polypeptide chain of CopZ, compared with the positions of the corresponding residues in $\mathrm{MNKr} 2$. The four residues which were mutated to lysine in $\mathrm{MNKr} 2 *$ are underlined. $\mathbf{b}$ Arrangement of the lysine residues of CopZ which is critical for interaction with CopY and these lysine residues modeled into the $\mathrm{MNKr} 2$ structure. The native lysines of $\mathrm{MNKr} 2$ which were not mutated are shown in red

experimentally well supported $[51,89,90]$ and proteinprotein interaction between CopZ and CopY was measured by surface plasmon resonance spectroscopy [91]. This interaction appeared to involve mainly R29, R30, R36, and R37 on one face of CopZ.

The second metal binding domain of the human Menkes ATPase, $\mathrm{MNKr}$ 2, exhibits essentially the same structure as CopZ, but cannot donate copper to CopY, presumably because it lacks the four prominent surface lysines; insertion of four corresponding lysine residues into $\mathrm{MNKr} 2$ resulted in a gain-of-function mutant protein which could donate copper to CopY (Fig. 7) [51]. This further supports the CopZ-CopY interactions and it will be interesting to see if the structure of CopY features the expected negative surface patch which could interact with CopZ.

\section{Function of CsoR-type copper sensors}

CsoR from Mycobacterium tuberculosis represents the founding member of a new and large class of prokaryotic $\mathrm{Cu}(\mathrm{I})$ regulators and its structure has recently been solved [53]. CsoR is tetrameric, with two monomers each forming a stable homodimer that adopts an antiparallel four-helixbundle architecture (Fig. 8). This represents a novel DNAbinding fold because it lacks the obvious candidate DNA binding domains present in winged-helix-type metalloregulators. Each CsoR homodimer binds two $\mathrm{Cu}^{+}$such that they bridge the two subunits. By X-ray absorption spectroscopy, it was shown that $\mathrm{Cu}^{+}$adopts a planar trigonal coordination involving two cysteines and a histidine residue [53].

CsoR has been shown to regulate the copZA operon of B. subtilis by copper-dependent derepression [92]. The

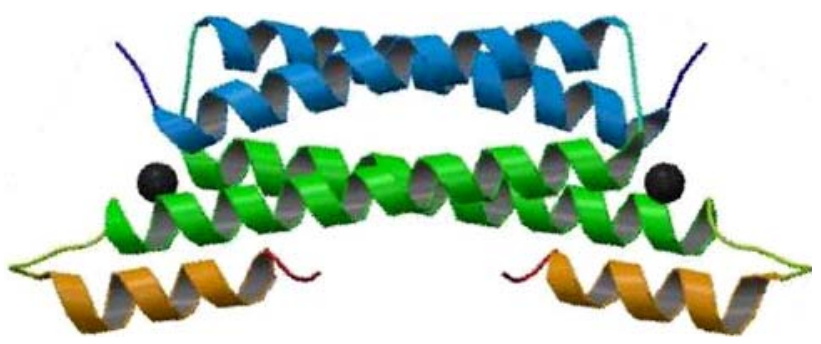

Fig. 8 Structure of a CsoR dimer from Mycobacterium tuberculosis. The two dark spheres represent bound $\mathrm{Cu}^{+}$(Protein Data Bank accession code $2 \mathrm{hh} 7$ )

operon encodes a CopZ-type copper chaperone and a copper-efflux ATPase. Two tetramers of apo-CsoR were shown to bind to a 30-bp DNA region overlapping the promoter of the copAZ operon. The CsoR-DNA binding was weakened upon $\mathrm{Cu}^{+}$binding, thereby acting as a copper-inducible repressor [53]. Clearly, CopY-type and CsoR-type repressors have very different structures and activation mechanisms to fulfill essential the same role. From an evolutionary point of view, it is interesting why and how such diverse mechanisms for copper regulation of gene expression evolved.

\section{Global responses to metal stress by Lactococcus lactis IL1403}

The CopY-type repressors of three Gram-positive bacterial species have been shown to recognize the TACAnnTGTA consensus motif, the cop box [57]. By performing a genomewide search for this conserved motif in L. lactis IL1403, Barré et al. found 28 genes whose operator regions harbor the cop box. Seven of these cop boxes were shown to interact with CopR, the CopY-type repressor of L. lactis, in a copper-responsive manner in vitro. The genes and operons associated with these cop boxes were termed "CopR regulon," which encompasses a total of 14 genes, organized into four operons and two monocistronic genes [50]. Three proteins of the CopR regulon, namely, YaiA, a glyoxylase, YtjD, a nitroreductase, and LctO, a lactate oxidase, were independently identified by two-dimensional gel electrophoresis and mass spectrometry as copperinduced proteins [4]. For other genes of the CopR regulon, induction by copper was verified by real-time quantitative PCR.

What is the function of these genes in copper homeostasis? As described above, the copRZA operon functions in the defense against copper toxicity. The function of the other genes, with the exception of $l c t O$, remains unclear. The $l c t O$ gene encodes an NAD-independent, flavin-containing lactate oxidase which converts lactate to pyruvate, using molecular oxygen. Induction of LctO was observed 
when L. lactis cells were challenged with copper under microaerobic growth conditions, whereas copper exposure under anaerobic growth conditions failed to induce $l c t O$. Since LctO requires oxygen for function, this makes biological sense, but suggests that another regulatory mechanism is also involved. Barré et al. [4] proposed that induction of lactate oxidase serves in the elimination of molecular oxygen, thereby attenuating formation of reactive oxygen radicals that could form under copper stress. Similarly, an oxygen-consuming NADH oxidase has been proposed to be involved in the defense against oxidative stress in Lactobacillus delbrueckii subsp. bulgaricus by removing oxygen and thereby preventing the generation of $\mathrm{H}_{2} \mathrm{O}_{2}$ and its reaction products [33].

\section{Copper ATPases}

All bacterial cells appear to feature copper-exporting ATPases to remove excess cytoplasmic copper. This function is accomplished by CopB in E. hirae and by CopA in L. lactis and other bacteria. Copper-importing ATPases, on the other hand, have only been described in E. hirae (CopA) and Synechocystis (CtaA). Whereas the role of E. hirae CopA in cell physiological function is still unclear, CtaA of Synechocystis has been shown to import copper for plastocyanin, a copper-containing thylakoid protein which functions in the photosynthetic electron transport chain [93].

Copper ATPases belong to the superfamily of P-type ATPases, a group of ATP-driven transport proteins characterized by unique signature motifs. The most prominent feature of this family of pumps is the formation of an acylphosphate intermediate (hence the name P-type ATPases), whereby the $\gamma$-phosphate of ATP phosphorylates the aspartic acid residue in the conserved motif DKTGT during the reaction cycle [94]. Other conserved features include consensus domains for ATP binding and energy transduction and a conserved, intramembranous proline residue with a function in ion transport $[95,96]$.

A subgroup of the of P-type ATPases, the CPx-type ATPases (also named heavy-metal ATPases or P1B-type ATPases [97, 98]), catalyzes the transport of transitionmetal or heavy-metal ions across the membrane [99]. The range of transported substrates is wide, including monovalent $\left(\mathrm{Cu}^{+}, \mathrm{Ag}^{+}\right)$as well as divalent $\left(\mathrm{Co}^{2+}, \mathrm{Zn}^{2+}, \mathrm{Cd}^{2+}\right.$, $\left.\mathrm{Hg}^{2+}, \mathrm{Pb}^{2+}\right)$ cations $[37,100]$. CPx-type ATPases differ from non-heavy-metal ATPases in several ways: (1) they feature only eight transmembrane helices, compared with non-heavy-metal ATPases, which feature ten [98, 101], (2) they contain one to six metal binding domains (one or two in bacteria) with a $\mathrm{CxxC}$ motif or a histidine-rich region at their N-terminus, (3) they possess a conserved HP

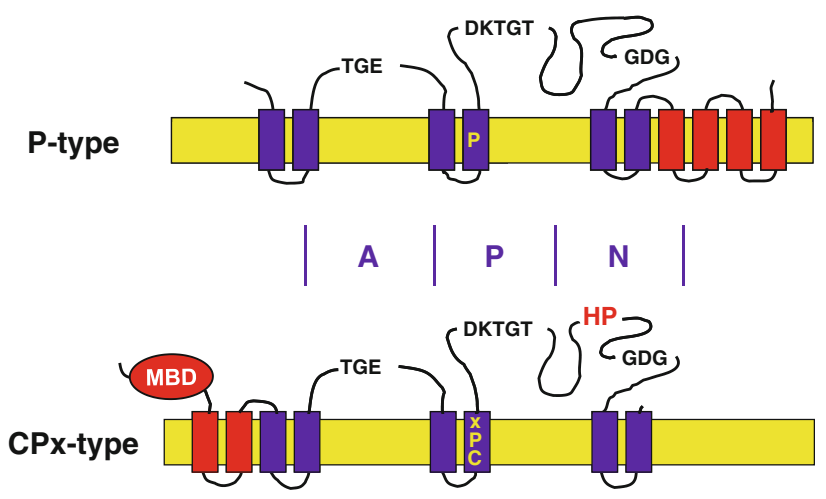

Fig. 9 P-type and CPx-type ATPases. The proteins are organized into three domains: $A$ actuator domain, $P$ phosphorylation domain, and $N$ nucleotide binding domain. Membranes are in yellow, and membrane helices common to both types of ATPases are shown in blue, additional membrane helices in red. The following sequence features are also indicated: MBD, heavy-metal binding domain with either a CxxC motif or a histidine-rich region, TGE, "kinase" motif; $\mathrm{P}$, intramembranous proline in non-heavy-metal ATPases; CPx, intramembranous $\mathrm{CPC}$, or $\mathrm{CPH}$ motif in heavy-metal ATPases; TKTGT, phosphorylation motif; GDG, ATP binding region; HP, conserved motif of unknown function in heavy-metal ATPases

sequence 34-43 residues C-terminal to the CPx motif, and (4) they possess a highly conserved $\mathrm{CPx}(\mathrm{x}$ is $\mathrm{C}$ or $\mathrm{H})$ motif in the sixth transmembrane helix (Fig. 9) [98]. The CPx motif is located in the most conserved core structure of the ATPases and includes the proline characteristic to all P-type ATPases.

So far, no complete structure of a CPx-type ATPase is available, but two models were proposed, based on either cryoelectron microscopy or intramolecular cross-linking $[102,103]$. Both models integrate partial structures available for some of the soluble domains and alignment with the structure of Serca1 [101]. Figure 10 shows the model for CopA by Lübben et al. [103]. The key differences from the model of $\mathrm{Wu}$ et al. [102] are the arrangement of the transmembrane helices and the $\mathrm{N}$-terminal metal binding domain. The metal binding domain of E. hirae CopA is arranged such that the CxxC metal binding motif is facing away from the bulk of the ATPase and is accessible to chaperones. The respective interacting surfaces exhibited a complementary electrostatic fit. Other orientations of the metal binding domain could be ruled out because they would violate the cross-linking geometry, resulting in false lengths. This contrasts with the model of Wu et al. [102], in which the metal binding domain has the opposite orientation, with the $\mathrm{Cu}^{+}$-binding $\mathrm{CxxC}$ domain facing the ATPase. The E. hirae CopA model shown in Fig. 10 also results in a more favorable arrangement of the conserved residues of the membrane ion channel (Fig. 11). There are two sites in the membrane domain of the copper ATPase which can be titrated with $\mathrm{Cu}^{+}$. According to GonzalesGuerrero et al. [104], site I is formed by two cysteines in 


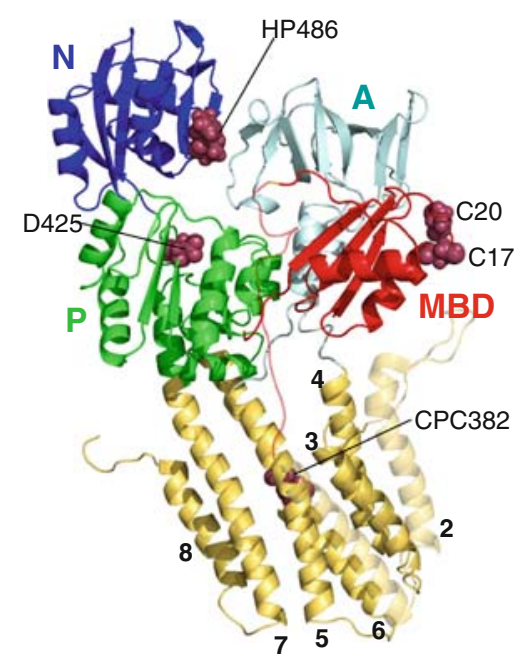

Fig. 10 Structure of the E. hirae CopA ATPase, modeled on the basis of intramolecular cross-linking data and known partial structures [103]. The metal binding domain is colored in red, the A-domain in grayish blue, the $\mathrm{N}$-domain in dark blue, the $\mathrm{P}$-domain in green, and the transmembranous domain in ochre, with helices 1 and 2 colored in a lighter shade owing to uncertainty in the position. Characteristic residues discussed in the text are shown in brown space-filling representation and are labeled
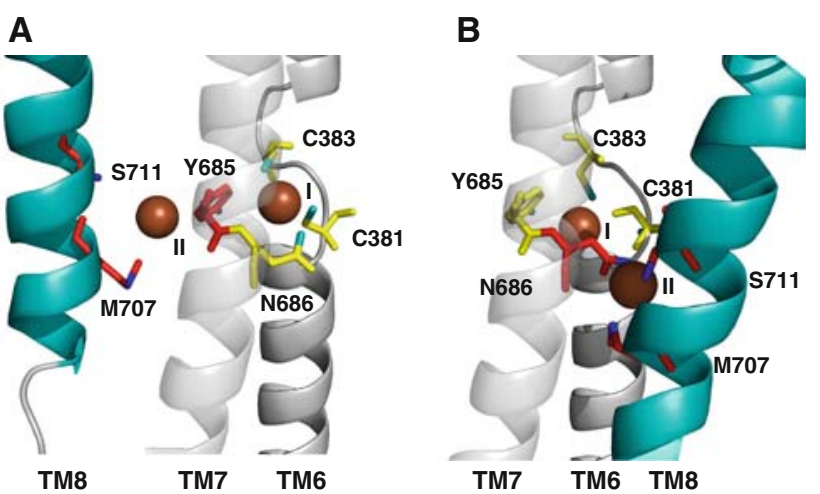

Fig. 11 Enlarged view of $\mathrm{Cu}^{+}$binding sites I and II located in transmembrane helices 6, 7, and 8. Ligands are placed as in the model of E. hirae CopA shown in a or the model of Archaeoglobus fulgidus CopA by Wu et al. [102]. b. $\mathrm{Cu}^{+}$site I (yellow residues), $\mathrm{C} 381$ and C383 in transmembrane helix 6 and N686 in transmembrane helix 7; $\mathrm{Cu}^{+}$site II (red residues), Y685 in transmembrane helix 7 and M707 and S711 in transmembrane helix 8 (cartoon courtesy of Gerd Kock and Mathias Lübben, Ruhr University)

transmembrane helix 6 and a tyrosine in transmembrane helix 7 and site II is formed by asparagine in transmembrane helix 7 and methionine and serine in transmembrane helix 8. In the E. hirae CopA model, the copper site I is formed by C381 and C383 in transmembrane helix 6, and N686 in transmembrane helix 7, and the copper site II is formed by Y685 in transmembrane helix 7 and M707 and S711 in transmembrane helix 8. This arrangement appears sterically much more favorable. Clearly, final information on the structure of the ion channel will have to await a high-resolution X-ray structure of a copper ATPase.

CopZ of $E$. hirae has been shown by surface plasmon resonance to interact with CopA [91]. It is assumed that $\mathrm{Cu}^{+}$imported by CopA is transferred to the CopZ copper chaperone, which subsequently delivers copper to the CopY repressor for induction of the cop operon or to other sites requiring copper. An interaction of CopZ of E. hirae with the copper-exporting ATPase CopB has also been shown (unpublished observation). In yeast, it has been shown that the CopZ-like chaperone, Atx1, delivers copper to the Ccc2 copper ATPase [105], which transfers copper across the membrane into the trans-Golgi network. Interaction of CopZ with the copper-exporting ATPase was also demonstrated in B. subtilis [106]. Although copper transfer from chaperones to the $\mathrm{N}$-terminal metal binding domains of CPx-type ATPases is now well documented, it has never been shown that this copper can actually be transported across the membrane. Rather, it has been suggested that the $\mathrm{N}$-terminus regulates the activity of the ATPase by domain interactions. Copper transport may thus require a separate copper-donation event to the membrane region of the ATPases [107].

There has been discussion of how it is mechanistically possible for copper ATPases of very similar primary structure to pump copper out of the cell in some cases (most copper ATPases), but into the cell in others (CtaA of Synechocystis, CopA of E. hirae). It is frequently ignored, even in textbooks, that the calcium ATPases of the eukaryotic plasma membrane and the sarcoplasmatic reticulum both catalyze calcium-proton antiport [108]. The ubiquitous eukaryotic NaK-ATPase catalyzes the exchange of three $\mathrm{Na}^{+}$for two $\mathrm{K}^{+}$, and the gastric $\mathrm{KH}$ ATPase exchanges $\mathrm{K}^{+}$for $\mathrm{H}^{+}$. There is still debate about the stoichiometry of these exchange mechanisms because proton movements are difficult to measure in biochemical experiments, but on the basis of structural and mechanistic considerations, it appears likely that cation antiport is an obligatory feature of P-type ATPases [108]. Copper ATPases would thus exchange $\mathrm{Cu}^{+}$for $\mathrm{H}^{+}$. The direction of transport of an ion by a P-type ATPase is not per se a property of the E1-E2 reaction cycle. From which side of the membrane an ion has access to the high-affinity or low-affinity binding site of the enzyme determines the direction of transport. A change in the transport direction probably requires relatively minor structural alterations to reverse the affinities for the incoming and the leaving ion at the respective side of the ion gate. The slow turnover of copper ATPases makes it difficult to study their transport properties in vitro and many open questions about copper transport will remain challenges for the future. 
Acknowledgments Some of the work described in this review was supported by grant 3100A0_122551 from the Swiss National Foundation and a grant from the International Copper Association.

\section{References}

1. Stiles ME (1996) Antonie Van Leeuwenhoek 70:331-345

2. Reeve WG, Tiwari RP, Kale NB, Dilworth MJ, Glenn AR (2002) Mol Microbiol 43:981-991

3. Galvez A, Abriouel H, Lopez RL, Ben ON (2007) Int J Food Microbiol 120:51-70

4. Barré O, Mourlane F, Solioz M (2007) J Bacteriol 189:59475954

5. Fraústo da Silva JJR, Williams RJP (1993) The biological chemistry of the elements. Oxford University Press, Oxford

6. Karlin KD (1993) Science 261:701-708

7. Cavet JS, Borrelly GP, Robinson NJ (2003) FEMS Microbiol Rev 27:165-181

8. Rapisarda VA, Chehin RN, De Las RJ, Rodriguez-Montelongo L, Farias RN, Massa EM (2002) Arch Biochem Biophys 405:87-94

9. Rodriguez-Montelongo L, Volentini SI, Farias RN, Massa EM, Rapisarda VA (2006) Arch Biochem Biophys 451:1-7

10. Arciero DM, Pierce BS, Hendrich MP, Hooper AB (2002) Biochemistry 41:1703-1709

11. Ellis MJ, Grossmann JG, Eady RR, Hasnain SS (2007) J Biol Inorg Chem 12:1119-1127

12. Lopez-Serrano D, Solano F, Sanchez-Amat A (2004) Gene 342:179-187

13. Tsai TY, Lee YH (1998) J Biol Chem 273:19243-19250

14. Brazeau BJ, Johnson BJ, Wilmot CM (2004) Arch Biochem Biophys 428:22-31

15. Chan SI, Chen KH, Yu SS, Chen CL, Kuo SS (2004) Biochemistry 43:4421-4430

16. Hullo MF, Moszer I, Danchin A, Martin-Verstraete I (2001) J Bacteriol 183:5426-5430

17. Kasting JF, Siefert JL (2002) Science 296:1066-1068

18. Crichton RR, Pierre J-L (2001) Biometals 14:99-112

19. Kaim W, Rall J (1996) Angew Chem Int Ed Engl 35:43-60

20. Ridge PG, Zhang Y, Gladyshev VN (2008) PLoS ONE 3:e1378

21. Kuper J, Llamas A, Hecht HJ, Mendel RR, Schwarz G (2004) Nature 430:803-806

22. Schwarz G, Mendel RR (2006) Annu Rev Plant Biol 57:623-647

23. Zhang Y, Gladyshev VN (2008) J Mol Biol 379:881-899

24. Furnes H, Banerjee NR, Muehlenbachs K, Staudigel H, de Wit M (2004) Science 304:578-581

25. Rasmussen B (2000) Nature 405:676-679

26. Fouquet Y, Von Stackelberg U, Charlou JL, Donval JP, Erzinger J, Foucher JP, Herzig P, Mühe R, Soakai S, Wiedicke M, Whitechurch H (1991) Nature 349:778-781

27. Turski ML, Thiele DJ (2009) J Biol Chem 284:717-721

28. Tottey S, Harvie DR, Robinson NJ (2005) Acc Chem Res 38:775-783

29. Kim BE, Nevitt T, Thiele DJ (2008) Nat Chem Biol 4:176-185

30. Magnani D, Solioz M (2007) In: Nies DH, Silver S (eds) Molecular microbiology of heavy metals. Springer, Heidelberg, pp 259-285

31. Changela A, Chen K, Xue Y, Holschen J, Outten CE, O'Halloran TV, Mondragon A (2003) Science 301:1383-1387

32. Rochat T, Gratadoux JJ, Gruss A, Corthier G, Maguin E, Langella P, van de Guchte M (2006) Appl Environ Microbiol 72:5143-5149

33. Marty-Teysset C, de la Torre F, Garel J (2000) Appl Environ Microbiol 66:262-267
34. Bolotin A, Wincker P, Mauger S, Jaillon O, Malarme K, Weissenbach J, Ehrlich SD, Sorokin A (2001) Genome Res 11:731-753

35. Macomber L, Rensing C, Imlay JA (2007) J Bacteriol 189:1616-1626

36. Macomber L, Imlay JA (2009) Proc Natl Acad Sci USA 106:8344-8349

37. Solioz M, Stoyanov JV (2003) FEMS Microbiol Rev 27:183195

38. Odermatt A, Suter H, Krapf R, Solioz M (1992) Ann N Y Acad Sci 671:484-486

39. Solioz M, Odermatt A (1995) J Biol Chem 270:9217-9221

40. Odermatt A, Krapf R, Solioz M (1994) Biochem Biophys Res Commun 202:44-48

41. Francis MS, Thomas CJ (1997) Mol Gen Genet 253:484-491

42. Wunderli-Ye H, Solioz M (2001) Biochem Biophys Res Commun 280:713-719

43. Chillappagari S, Miethke M, Trip H, Kuipers OP, Marahiel MA (2009) J Bacteriol 191:2362-2370

44. Kim HJ, Graham DW, DiSpirito AA, Alterman MA, Galeva N, Larive CK, Asunskis D, Sherwood PM (2004) Science 305:1612-1615

45. Balasubramanian R, Rosenzweig AC (2008) Curr Opin Chem Biol 12:245-249

46. Mellano MA, Cooksey DA (1988) J Bacteriol 170:2879-2883

47. Singleton C, Banci L, Ciofi-Baffoni S, Tenori L, Kihlken MA, Boetzel R, Le Brun NE (2008) Biochem J 411:571-579

48. Singleton C, Le Brun NE (2009) Dalton Trans 28:688-696

49. Odermatt A, Suter H, Krapf R, Solioz M (1993) J Biol Chem 268:12775-12779

50. Magnani D, Barré O, Gerber SD, Solioz M (2008) J Bacteriol 190:536-545

51. Cobine PA, George GN, Jones CE, Wickramasinghe WA, Solioz M, Dameron CT (2002) Biochemistry 41:5822-5829

52. Arnesano F, Banci L, Bertini I, Ciofi-Baffoni S, Molteni E, Huffman DL, O'Halloran TV (2002) Genome Res 12:255-271

53. Liu T, Ramesh A, Ma Z, Ward SK, Zhang L, George GN, Talaat AM, Sacchettini JC, Giedroc DP (2007) Nat Chem Biol 3:60-68

54. Strausak D, Solioz M (1997) J Biol Chem 272:8932-8936

55. Hasman H, Kempf I, Chidaine B, Cariolet R, Ersboll AK, Houe H, Bruun Hansen HC, Aarestrup FM (2006) Appl Environ Microbiol 72:5784-5789

56. Vats N, Lee SF (2001) Microbiology 147:653-662

57. Portmann R, Poulsen KR, Wimmer R, Solioz M (2006) Biometals 19:61-70

58. Mitrakul K, Loo CY, Hughes CV, Ganeshkumar N (2004) Oral Microbiol Immunol 19:395-402

59. Outten FW, Outten CE, Hale J, O'Halloran TV (2000) J Biol Chem 275:31024-31029

60. Gaballa A, Cao M, Helmann JD (2003) Microbiology 149:3413-3421

61. Smaldone GT, Helmann JD (2007) Microbiology 153:41234128

62. Lin SJ, Culotta VC (1995) Proc Natl Acad Sci USA 92:37843788

63. O'Halloran TV, Culotta VC (2000) J Biol Chem 275:2505725060

64. Odermatt A, Solioz M (1995) J Biol Chem 270:4349-4354

65. Leary SC, Kaufman BA, Pellecchia G, Guercin GH, Mattman A, Jaksch M, Shoubridge EA (2004) Hum Mol Genet 13:18391848

66. Schulze M, Rodel G (1988) Mol Gen Genet 211:492-498

67. Hamza I, Gitlin JD (2002) J Bioenerg Biomembr 34:381-388

68. Balatri E, Banci L, Bertini I, Cantini F, Ciofi-Baffoni S (2003) Structure 11:1431-1443 
69. Mattatall NR, Jazairi J, Hill BC (2000) J Biol Chem 275:2880228809

70. Abriata LA, Banci L, Bertini I, Ciofi-Baffoni S, Gkazonis P, Spyroulias GA, Vila AJ, Wang S (2008) Nat Chem Biol 4:599601

71. Banci L, Bertini I, Ciofi-Baffoni S, Gerothanassis IP, Leontari I, Martinelli M, Wang S (2007) Structure 15:1132-1140

72. Davis AV, O'Halloran TV (2008) Nat Chem Biol 4:148-151

73. Rosenzweig AC (2001) Acc Chem Res 34:119-128

74. Wimmer R, Herrmann T, Solioz M, Wüthrich K (1999) J Biol Chem 274:22597-22603

75. Kihlken MA, Leech AP, Le Brun NE (2002) Biochem J 368:729-739

76. Kihlken MA, Singleton C, Le Brun NE (2008) J Biol Inorg Chem 13:1011-1023

77. Pufahl RA, Singer CP, Peariso KL, Lin S, Schmidt PJ, Fahrni CJ, Culotta VC, Penner-Hahn JE, O'Halloran TV (1997) Science 278:853-856

78. Lu ZH, Solioz M (2001) J Biol Chem 276:47822-47827

79. Van Melckebeke H, Vreuls C, Gans P, Filee P, Llabres G, Joris B, Simorre JP (2003) J Mol Biol 333:711-720

80. Garcia-Castellanos R, Mallorqui-Fernandez G, Marrero A, Potempa J, Coll M, Gomis-Ruth FX (2004) J Biol Chem 279:17888-17896

81. Wittman V, Wong HC (1988) J Bacteriol 170:3206-3212

82. Himeno T, Imanaka T, Aiba S (1986) J Bacteriol 168:11281132

83. Cantini F, Banci L, Solioz M (2009) Biochem J 417:493-499

84. Lewis RA, Curnock SP, Dyke KG (1999) FEMS Microbiol Lett 178:271-275

85. Bird AJ (2008) Adv Microb Physiol 53:231-267

86. Portmann R, Magnani D, Stoyanov JV, Schmechel A, Multhaup G, Solioz M (2004) J Biol Inorg Chem 9:396-402

87. Sharma VK, Hackbarth CJ, Dickinson TM, Archer GL (1998) J Bacteriol 180:2160-2166

88. Cobine P, Jones CE, Wickramasinghe WA, Solioz M, Dameron CT (2002) In: Massaro EJ (ed) Handbook of copper pharmacology and toxicology. Humana Press, Totowa, pp 177-186
89. Cobine P, Wickramasinghe WA, Harrison MD, Weber T, Solioz M, Dameron CT (1999) FEBS Lett 445:27-30

90. Cobine PA, Jones CE, Dameron CT (2002) J Inorg Biochem 88:192-196

91. Multhaup G, Strausak D, Bissig K-D, Solioz M (2001) Biochem Biophys Res Commun 288:172-177

92. Ma Z, Cowart D, Scott R, Giedroc DP (2009) Biochemistry 48:3325-3334

93. Tottey S, Rich PR, Rondet SA, Robinson NJ (2001) J Biol Chem 276:19999-20004

94. Pedersen PL, Carafoli E (1987) Trends Biochem Sci 12:146150

95. Toyoshima C, Mizutani T (2004) Nature 430:529-535

96. Toyoshima C, Nomura H, Sugita Y (2003) Ann N Y Acad Sci 986:1-8

97. Lutsenko S, Kaplan JH (1995) Biochemistry 34:15607-15613

98. Solioz M, Vulpe C (1996) Trends Biochem Sci 21:237-241

99. Axelsen KB, Palmgren MG (1998) J Mol Evol 46:84-101

100. Rensing C, Ghosh M, Rosen BP (1999) J Bacteriol 181:58915897

101. Toyoshima C, Nakasako M, Nomura H, Ogawa H (2000) Nature 405:647-655

102. Wu CC, Rice WJ, Stokes DL (2008) Structure 16:976-985

103. Lübben M, Portmann R, Kock G, Stoll R, Young MM, Solioz M (2009) Biometals 22:363-375

104. Gonzalez-Guerrero M, Eren E, Rawat S, Stemmler TL, Arguello JM (2008) J Biol Chem 283:29753-29759

105. Huffman DL, O'Halloran TV (2001) Annu Rev Biochem 70:677-701

106. Radford DS, Kihlken MA, Borrelly GP, Harwood CR, Le Brun NE, Cavet JS (2003) FEMS Microbiol Lett 220:105-112

107. Arguello JM, Gonzalez-Guerrero M (2008) Structure 16:833834

108. Niggli V, Sigel E (2008) Trends Biochem Sci 33:156-160 